\title{
Lowe Syndrome: report of five cases
}

\begin{abstract}
Authors
Marta Liliane de Almeida Maia ${ }^{1}$

Maria Luiza Dautro Moreira do $\mathrm{Val}^{2}$

Camila Penteado Genzani²

Fernanda Alves Thomaz Fernandes ${ }^{2}$

Maria Cristina de Andrade ${ }^{2}$

João Tomás de Abreu Carvalhaes $^{2}$

${ }^{1}$ Division of Pediatric Nephrology, Departament of Pediatrics, UNIFESPEPM - Universidade Federal de São Paulo- SP- Brazil; Division of Pediatric Nephrology, Hospital Infantil Darcy Vargas, São

Paulo, SP, Brazil

2Division of Pediatric Nephrology, Departament of Pediatrics, UNIFESPEPM - Universidade Federal de São Paulo- SP- Brazil
\end{abstract}

Submitted: 20/12/2009 Accepted: 25/01/2010

Correspondence to: Maria Cristina de Andrade Rua Gaivota, no 754, ap. 71, Moema - São Paulo/SP CEP: 04522-032

Tel./fax: (11) 5572-6728 E-mails: andrademc@globo. com; mariacristinaandrade@ mbapediatria.com.br

Institution: Division of Pediatric Nephrology, Departament of Pediatrics, UNIFESP-EPM- Universidade Federal de São Paulo

\section{Abstract}

Introduction: Lowe Syndrome, or Oculocerebrorenal Dystrophy (OCRL), has a recessive inheritance linked to $\mathrm{X}$ chromosome. It presents cataracts and glaucoma, delay in neuropsychomotor development, cognitive deficits, and renal Fanconi syndrome. Objective: Describe five patients with OCRL, attended at Tubulopathy outpatient clinic. Method: We performed a retrospective assessment of 5 male patient clinical charts of OCRL patients. Results: Mean age at first consultation was 76.5 and mean follow up interval was 30.5 months (8-53 months). Symptoms and clinical signs included cataracts and nystagmus. Neuropsychomotor development and weight and height deficits were present in whole cases, as well as polyuria, polydipsia, and intestinal constipation, metabolic acidosis, phosphaturia, bicarbonaturia, proteinuria, hypercalciuria, hyperuricosuria. Nephrocalcinosis was identified in one, renal lithiasis in three, and reduced kidney size in two patients. We found pathological fractures and rachitism in two, bone rarefaction and delay of bone age in all of the patients. One patient presented a reduction in the rhythm of glomerular filtration. Therapeutically, all patients received alkali, phosphorus and vitamin $\mathrm{D}$ reposition in addition to a dietary orientation adequate to their needs. Conclusion: This study emphasizes the importance of early diagnosis and medico-nutritional follow-up, to avoid complications related to metabolic disturbances.

Keywords: oculocerebrorenal syndrome; renal tubular acidosis, rickets; Fanconi syndrome.

[J Bras Nefrol 2010;32(2):216-221]@Elsevier Editora Ltda.

\section{INTRODUCTION}

Lowe Syndrome (oculocerebrorenal syndrome), described for the first time by Lowe (1952), is an X-linked pathology that is recessively transmitted owing to mutations in the OCRL1 gene. ${ }^{1-3}$ This gene is located on the X q25-q26 chromosome, which encodes the phosphatidylinositol enzyme $(4,5)$ biphosphate 5 - phosphatase present in the Golgi complex. ${ }^{4}$ There are over 88 mutations already described. Mutation of this enzyme culminates in the intracellular accumulation of its PIP2 substrate, where PIP2 is a phospholipid that plays an essential role in cellular processes such as intracellular signaling, protein trafficking, and polymerization of the cytoskeleton actin. ${ }^{4}$

Oculocerebrorenal syndrome (OCRL) is characterized by multi-systemic congenital alterations involving the eyes, central nervous system (CNS), and kidneys. ${ }^{5-7}$

Certain clinical manifestations are usually present, including congenital cataract and glaucoma, global delay in neuropsychomotor development (NPMD), hypotonia and hyporeflexia, serious cognitive deficits (in approximately $50 \%$ of cases), and renal tubular abnormalities (Fanconilike). ${ }^{8}$ Convulsive crisis, cryptorchidy, and deafness are also found to be associated with other ocular alterations, such as nystagmus, enophthalmia, and miotic pupils. ${ }^{4}$ Skeletal muscle alterations, such as articular hyper-mobility, hip luxation, rickets, pathological fractures, and weight and height deficits, can occur as a consequence of tubular alterations. ${ }^{9}$

The Fanconi syndrome appeared in these patients during the first year of their lives, and it is primarily characterized by generalized aminoaciduria and reduction 
in urea, phosphate, and bicarbonate re-absorption. Proteinuria is always present; however, the intensity, the age when it begins, and the rate of evolution with accompanying loss of renal function are variable. 4

Since this is an X-linked disorder, the mothers of the affected children can present central posterior lenticular opacification even though this is normally asymptomatic. ${ }^{10}$

Early diagnosis is necessary for immediate therapeutic intervention to decrease the likelihood of complications.

Although genetic study of Lowe Syndrome is advanced in study centers, patients in daily clinical practice are generally diagnosed through clinical manifestations and laboratory tests pertinent to the disease. In the light of this, the following is a descriptive study of this pathology.

\section{Methods}

Five male patients in the tubulopathy outpatient clinic of the Pediatric Nephrology Department of the Department of Pediatrics at UNIFESP-EPM were studied between June 2002 and November 2006.

Clinical, laboratory, and imaging (kidney and urinary tract ultrasound-USG, long bones X-RAY) data, as well as fundus examinations, were collected retrospectively through the revision of charts.

Patient assessment was based on clinical history, physical examination, serial anthropometric measures, serum and urinary electrolyte levels (sodium, potassium, calcium, phosphate, magnesium, chlorine), uric acid, creatinine clearance, venous blood gas analysis, and urinalysis.

The assessment of electrolytes urinary excretion was conducted through its relationship in the isolated sample with urinary creatinine. Analysis data of phosphorus and uric acid were performed via the tubular re-absorption rate and excretion fraction, respectively.

Other complementary analyses were performed according to the patient's needs and availability of laboratorial services.

Biochemical measurement of urinalysis test was performed via a dipstick reading with a Multistik (Bayer), and microscope urinary sediment was analyzed through qualified technicians reading. Serum electrolyte and urinary dosage in isolated samples were performed in an automated way by the ADVIA 1650 device (Bayer). Venous blood gas analysis was performed by an ABL - 700 Radiometer. All examinations were performed in the Clinical Analysis Lab at the Hospital São Paulo.
Ophthalmologic assessments were performed by a team of the Department of Ophthalmology of UNIFESP-EPM; imaging exams were conducted by the Department of Imaging Diagnosis of UNIFESPEPM.

Glomerular filtration rate (GFR) was estimated by the creatinine clearance, which was calculated based on Schwartz formula ${ }^{11}$ and classified according to KDOQI 2006. ${ }^{12}$

The following values were used in this study as references for urinary excretions in isolated urinary samples: calcium/creatinine $<0.2,{ }^{13,14}$ uric acid fractional excretion $(\mathrm{FE})<10 \%,{ }^{15}$ and phosphorus reabsorption rate $>80 \% .^{16}$

Evaluation of five patients with Lowe syndrome allowed us to study clinical, laboratorial, and nutritional evolution under therapeutic treatment proposed for the disorder over the study period.

In this study, each patient was accompanied by a team of pediatric nephrologists and nutritionists. According to the literature, all were treated with oral supplement of sodium bicarbonate, and $80-100 \mathrm{mg} /$ $\mathrm{kg} /$ day of L-carnitine. Three (3/5) used a formula containing phosphorus (Neutrophos K $250 \mathrm{mg} \mathrm{P}+14 . .^{25}$ $\mathrm{mEq} \mathrm{K} / 5 \mathrm{~mL})$, three (3/5) used calcitriol, and four (4/5) used an angiotensin converting enzyme inhibitor (captopril $0.5-2.0 \mathrm{mg} / \mathrm{kg} / \mathrm{day}$ ). Additionally, all consumed a diet in which calories and quantities of macro and micro-nutrients were specifically adjusted to individual needs.

\section{Results}

Table 1 shows the clinical characteristics of the patients studied related to gender, age at diagnosis, follow-up time, presence of cataracts, fractures, rickets, and delay in NPMD. Age at the first consultation varied between 2 and 151 months (medium 76.5 months) with a mean follow-up time of 30.5 months (minimum 8 and maximum 53).

According to the standard of genetic transmission (recessively linked to $\mathrm{X}$ ), all patients were males. Of the patients described, only one (patient 5) had a positive family history with two affected members.

All children presented a delay in neuropsychomotor development and cataracts at an early age; the cataracts can be corrected surgically. Despite early treatment, all patients presented a visual precision deficit and ocular nystagmus. One of them (patient 2) progressed with unilateral glaucoma controlled by drug treatment and keloid lesion in the contralateral cornea that required surgical intervention. Patients 
Table 1

SUMMARY OF CLINICAL DATA AT ENTRY AND AT THE END OF THE STUDY PERIOD FOR FIVE CHILDREN WITH LOWE SYNDROME

\begin{tabular}{|c|c|c|c|c|c|c|c|c|c|c|c|}
\hline Patient & Gender & $\begin{array}{l}\text { Initial } \\
\text { age } \\
\text { (m) }\end{array}$ & $\begin{array}{l}\text { Final } \\
\text { age } \\
(\mathrm{m})\end{array}$ & $\begin{array}{c}\text { Diagnostic } \\
\text { age } \\
\text { (m) }\end{array}$ & $\begin{array}{c}\text { Follow up } \\
\text { time } \\
\text { (m) }\end{array}$ & Cataract & Fracture & Rickets & Delay & Cryptorchidy & Audiometry \\
\hline 1 & M & 89 & 142 & 36 & 53 & Y & Y & Y & Y & Right & Normal \\
\hline 2 & M & 27 & 62 & 24 & 35 & Y & $\mathrm{N}$ & Y & Y & Left & Deficit \\
\hline 3 & $M$ & 105 & 113 & 104 & 8 & Y & Y & Y & Y & Right & Normal \\
\hline 4 & M & 151 & 163 & 17 & 12 & Y & $\mathrm{N}$ & Y & Y & Right & NA \\
\hline 5 & M & 2 & 16 & 1 & 14 & Y & $\mathrm{N}$ & Y & Y & $\mathrm{N}$ & Normal \\
\hline
\end{tabular}

$\mathrm{M}=$ male; $\mathrm{Y}=$ yes; $\mathrm{N}=$ no; $\mathrm{NA}=$ not available; NPMD = delay in neuropsychomotor development; $\mathrm{m}=$ months.

1 and 4 presented unilateral amaurosis secondary to retinal detachment. One of the mothers presented cataracts at an early age.

The diagnosis was performed based on the clinical analysis, phenotype, and complementary exams.

Cataracts, which were bilateral in most cases and nystagmus were the main clinical signs in the first months of life. The delay in neuropsychomotor development was present in all cases during the first months. Appendicular and axial hypotonia were noticed in four of the five patients, and mental retardation appeared in all, to different degrees.

All of the patients described presented delays in the acquisition of language, and none are literate. Four patients out of five do not walk, and one (1/5) began to walk at the age of five.

Two patients presented a history of pathological fractures, and the X-Ray allowed us to document bone rarefaction through simple long bone radiography in three, osteoporosis (bone densitometry L2-4 was $-3 \mathrm{SD}$ ) in one, and delay in bone ageing in three patients.

It was observed that all patients presented polyuria, polydipsia and intestinal constipation. Of the five patients, four (1, 2, 3 and 4) presented unilateral cryptorchidy that was corrected surgically.

Laboratory data revealed metabolic acidosis (venous serum bicarbonate between 16 and 21 with an average of 18), urinary $\mathrm{pH}$ varying from 6.0 to 8.5 , phosphaturia, bicarbonaturia, proteinuria, hypercalciuria, and hyperuricosuria. In relation to phosphaturia, it is necessary to highlight that patient number 5 presented a normal initial phosphaturia; at the end of the follow-up period, however, this patient had already presented a decrease in phosphorus re-absorption rates. This patient was diagnosed in the first month of life, due to a positive family history, when there is rare evidence of alterations in renal tubular function.

As demonstrated in table 2, three patients presented renal lithiasis, one nephrocalcinosis, and two had normal ultrasonography for their age during the follow-up period.

In table 3, the initial and final nutritional rates of each patient are shown. All patients presented weight and height deficits as well as small stature.

To compare the mean nutritional evolution at the beginning and end of the follow-up period, paired ttests were used. The table below shows the descriptive levels ( $\mathrm{p}$-values) obtained for each test. No statistically significant improvement (using a 5\% significance cut-off) in any index was noticed (table 4).

According to table 5, two patients presented a decreased GFR during the initial assessment. During follow-up period, only one of them (patient 4) showed a GFR that persisted below the expected range. Patient number 5 initially presented a clearance below $90 \mathrm{~mL} / \mathrm{min}$, but this was normal for his age at the time of assessment.

For treatment of metabolic disturbances, all patients received alkali therapy (sodium bicarbonate or potassium citrate). Three patients received reposition of phosphorus and active vitamin D in addition to diets adapted to their needs. All patients used L-carnitine (between 80 and $100 \mathrm{mg} / \mathrm{kg} / \mathrm{day}$ ).

\section{Discussion}

Lowe syndrome is a rare disease with unknown incidence rates in Brazil. The OCRL syndrome was the first human pathology attributed to a defect in the inositol phosphatase intracellular signal pathway. ${ }^{17}$ Although the main clinical manifestations involve CNS, eyes, and kidneys, the expression of the OCRL-1 


\section{Table 2 RENAL DYSFUNCTION IN OCRL}

\begin{tabular}{|c|c|c|c|c|c|c|c|}
\hline Patient & $\begin{array}{c}\text { Urinary } \\
\mathrm{pH}\end{array}$ & $\begin{array}{c}\text { Tubular } \\
\text { phosphate }\end{array}$ & Hypercalciuria & $\begin{array}{l}\text { Serum } \\
\text { acid }\end{array}$ & $\begin{array}{l}\text { Fósforo phos- } \\
\text { phorus (mg/dL) }\end{array}$ & Proteinuria & $\begin{array}{c}\text { Renal } \\
\text { ultrasonography }\end{array}$ \\
\hline 1 & 8.5 & $52 \%$ & Y & Increased & 2.8 & S & $\begin{array}{c}\text { Nephrocalcinosis + } \\
\text { Lithiasis }\end{array}$ \\
\hline 2 & 8.5 & $74 \%$ & Y & Increased & 2.6 & S & Lithiasis \\
\hline 3 & 7 & $73 \%$ & Y & Increased & 2 & S & Lithiasis \\
\hline 4 & 6 & $68 \%$ & Y & Increased & 4.9 & S & Normal \\
\hline 5 & 7 & $94 \%$ & Y & Increased & 5.1 & S & Normal \\
\hline
\end{tabular}

$\mathrm{Y}=$ yes; $\mathrm{N}=\mathrm{no} ; \mathrm{FE}=$ fractional excretion.

\section{Table 3 NUtRITIONAL FOLLOW-UP}

\begin{tabular}{ccccccccc} 
Patient & \multicolumn{2}{c}{$Z-\mathrm{W} / \mathrm{H}$} & \multicolumn{2}{c}{$\mathrm{Z}-\mathrm{H} / \mathrm{A}$} & \multicolumn{2}{c}{$\mathrm{Z}-\mathrm{W} / \mathrm{A}$} & \multicolumn{2}{c}{$\mathrm{BMI}$} \\
\hline & Initial & Final & Initial & Final & Initial & Final & Initial & Final \\
\hline 1 & -3.02 & -1.54 & -6.39 & -6.45 & -5.09 & -4.01 & 12.04 & 13.23 \\
2 & -1.31 & -1.49 & -6.48 & -6.19 & -4.76 & -4.2 & 15.11 & 14.7 \\
3 & -1.72 & -0.96 & -5.53 & -5.6 & -3.88 & -3.54 & 13.27 & 14.37 \\
4 & 0.63 & 1.52 & -3.31 & -3.49 & -2.21 & -2.28 & 16.92 & 17.93 \\
5 & -1.96 & -2.11 & -0.88 & -1.09 & -2.06 & -2.22 & 14.46 & 14.37
\end{tabular}

$\mathrm{BMI}=$ body mass index; $\mathrm{Z}-\mathrm{W} / \mathrm{H} \mathrm{Z}=$ score weight/height; $\mathrm{Z}-\mathrm{A} / \mathrm{l}=$ score height/age $; \mathrm{Z}-\mathrm{H} / \mathrm{A}=$ score weight/age.

\section{Table 4 Nutritional Follow-UP}

\begin{tabular}{lccc}
\multicolumn{3}{c}{ Means } \\
\hline Index & Initial & Final & Value-p \\
\hline Z-W/H & -1.476 & -0.916 & 0.154 \\
Z-H/A & -4.518 & -4.564 & 0.633 \\
Z-W/A & -3.600 & -3.250 & 0.195 \\
BMI & 14.360 & 14.920 & 0.171 \\
\hline
\end{tabular}

\section{Table 5}

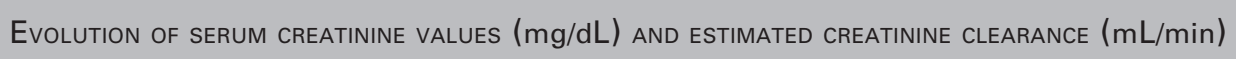

\begin{tabular}{ccccc} 
Patient & $\begin{array}{c}\text { Creatinine } \\
\text { (initial) }\end{array}$ & Clearance & $\begin{array}{c}\text { Creatinine } \\
\text { (final) }\end{array}$ & Clearance \\
\hline 1 & 0.7 & 68.3 & 0.7 & 77.7 \\
2 & 0.5 & 74.2 & 0.2 & 225.5 \\
\hline
\end{tabular}


gene is not restricted to these systems but also includes the bladder, testicles, uterus, uterine tube, stomach, intestines, liver, pancreas, and spleen. However, the involvement of such organs is not clinically evident in Lowe Syndrome. ${ }^{18}$

Hypotonia, hypo or arreflexia, and progressive retardation in neurological, psychological and motor development are present during the neonatal period in the majority of Lowe Syndrome cases. ${ }^{19}$ Some researchers report an improvement in the neurological deficit with rehabilitation programs, but this finding was verified in only two patients. Due to the unfavorable socio-economic status of the majority of the population assisted in our service, only those two patients are involved in rehabilitation programs.

Cataracts observed during the first months of life occurred in $100 \%$ of the patients affected and are thus considered to be one of the main characteristics of the disease. They should be considered an element that corroborates clinical data and suggests referral of the patient. Despite the fact that all of our patients were male and presented cataracts, rickets, and delayed NPMD, the majority (4/5) were diagnosed lately.

Fanconi syndrome is the main renal disorder associated with Lowe syndrome. This generally occurs in the first year of life, producing the main metabolic disturbances of hypophosphatemia, hypokalemia, metabolic acidosis, hyperuricosuria, proteinuria, and polyuria. ${ }^{20}$ The data observed agree with those in the literature. There was no initial detection of a metabolic disturbance (except for proteinuria) in patient five, but this can be attributed to the early age of diagnosis. Metabolic disturbance evolved to include phosphaturia during follow-up.

In addition to the clinical-laboratorial findings compatible with alteration of the proximal tubular function that we observed in the studied patients, all of them presented predominantly alkaline urinary $\mathrm{pH}$ values and positive urinary anion gaps $(\mathrm{Cl}<\mathrm{Na}+\mathrm{K})$. These findings point to a possible defect in the excretion of hydrogen, which was originally cited by Lowe et al. ${ }^{1}$ The OCRL expression of the distal nephron can be responsible for this defect. ${ }^{18}$ Nephrocalcinosis, frequently associated with distal tubular acidosis but not to the Fanconi syndrome, is also a characteristic of this pathology. According to a report in the literature, nephrocalcinosis provides further evidence of distal nephron involvement ${ }^{18}$ and was observed in one of the studied patients.

Biopsy data in children older than five years demonstrated sclerosed, hyalinized, or diffusely hypercellular glomeruli with thickened basement membrane and interstitial fibrosis. Tubular abnormalities varied from minor to severe. ${ }^{17}$ It is believed that there is an anatomical and clinical correspondence between the histopathologic stage and clinical manifestations.

According to the literature, evolution is marked by a progression to terminal renal failureduring the second decade of life. ${ }^{4}$ Except for one case at stage II (KDOQI), all cases described in this work presented normal renal function. This can be explained by the young age of the studied children. Note that the patient with the functional deficit is the oldest involved in the study.

In agreement with the literature, we did not observe significant collateral effects with the medication used.

Chronic acidosis disturbs weight and height development. ${ }^{21}$ In our individualized nutritional followup, we observed a slightly favorable evolution in the majority of the analyzed nutritional parameters after a partial or total correction of the hydroelectrolytic and acid-base conditions.

After descriptive analysis of the means and considering the small size of the sample, however, we observe a nonsignificant difference between the initial and final means of the Z-W/H, Z-W/A, and BMI. It is possible that these differences could reach significance at $5 \%$ if the sample size were increased.

It is well known that children in nutritional recuperation initially recover weight to further present a "catch up" in growth. In this way, we would expect that the first index, in which we would notice recuperation, or at least improvement, is the weight/ height index. This would be followed by weight/age and finally height, which would improve the height/ age index. Many patients presented bone deformities due to hypophosphatemia and an unfavorable socioeconomic situation that impeded physiotherapeutic treatments that minimize such deformities. This suggests an explanation for why there was no difference in the height/age index in the studied sample.

There is no specific treatment for this pathology. The aim of the treatment is to improve the clinical evolution of these patients, minimize the complications inherent to the disease, and postpone the evolution to terminal renal disease. Metabolic acidosis, electrolytic disturbances and rickets should be corrected and ocular pathologies handled surgically.

It is also necessary to emphasize the importance of early diagnosis and genetic counseling to avoid reoccurrence within the same family. 


\section{References}

1. Lowe CU, Terrey M, Mac LE. Organic-aciduria, decreased renal ammonia production, hydrophthalmos, and mental retardation; a clinical entity. AMA 1952; 83(2):164-84.

2. Bickel H, Thursby-Pelham DC. Hyperamino-aciduria in Lignac-Fanconi disease, in galactosaemia and in an obscure syndrome. Arch Dis Child 1954; 29(145):22431.

3. Richards W, Donnell GN, Wilson WA, Stowens D, Perry T. The Oculo-Cerebro-Renal Syndrome of Lowe. Am J Dis Child 1960; 109:185-203.

4. Loi M. Lowe syndrome. Orphanet J Rare Dis 2006; $1(1): 16$.

5. Addis M, Loi M, Lepiani C, Cau M, Melis MA. OCRL mutation analysis in Italian patients with Lowe syndrome. Hum Mutat 2004; 23(5):524-5.

6. Cho HY, Lee BH, Choi HJ, Ha IS, Choi Y, Cheong HI. Renal manifestations of Dent disease and Lowe syndrome. Pediatr Nephrol (Berlin, Germany) 2008; 23(2):243-9.

7. Chabaa L, Monnier N, Dahri S, Jorio M, Lunardi J, Chabraoui L. Oculo-cerebro-renal Lowe syndrome: clinical, biochemical and molecular studies in a Moroccan patient. Ann Biol Clin 2006; 64(1):53-9.

8. Faucherre A, Desbois P, Nagano F et al. Lowe syndrome protein Ocrl1 is translocated to membrane ruffles upon Rac GTPase activation: a new perspective on Lowe syndrome pathophysiology. Hum Mol Genet 2005; 14(11):1441-8.

9. Holtgrewe JL, Kalen V. Orthopedic manifestations of the Lowe (oculocerebrorenal) syndrome. J Pediatr Orthop 1986; 6(2):165-71.

10. Johnston SS, Nevin NC. Ocular manifestations in patients and female relatives of families with the oculocerebrorenal syndrome of Lowe. Birth defects original article series, 1976; 12(3):569-77.
11. Schwartz GJ, Feld LG, Langford DJ. A simple estimate of glomerular filtration rate in full-term infants during the first year of life. J Pediatr 1984; 104(6):849-54.

12. Stojanovic N, Cvoriscec D, Rogic D, Jelakovic B. The estimation of glomerular filtration rate using prediction equations. Lijec Vjesn 2006; 128(5-6):174-9.

13. Matos V, van Melle G, Boulat O, Markert M, Bachmann C, Guignard JP. Urinary phosphate/creatinine, calcium/ creatinine, and magnesium/creatinine ratios in a healthy pediatric population. J Pediatr 1997; 131(2):252-7.

14. Butani L, Kalia A. Idiopathic hypercalciuria in children-how valid are the existing diagnostic criteria? Pediatr Nephrol (Berlin, Germany) 2004; 19(6):577-82.

15. Steinhauslin F, Burnier M, Magnin JL et al. Fractional excretion of trace lithium and uric acid in acute renal failure. J Am Soc Nephrol 1994; 4(7):1429-37.

16. Walton RJ, Bijvoet OL. Nomogram for derivation of renal threshold phosphate concentration. Lancet 1975; 2(7929):309-10.

17. Gropman A, Levin S, Yao L et al. Unusual renal features of Lowe syndrome in a mildly affected boy. Am J Med Genet 2000; 95(5):461-6.

18. Erb BC, Velazquez H, Gisser M, Shugrue CA, Reilly RF. cDNA cloning and localization of OCRL-1 in rabbit kidney. Am J Physiol 1997; 273(5 Pt 2):F790-5.

19. Wang CL, Liu CY, Yuh YS, Chu ML. Lowe syndrome: report of one case. Zhonghua Minguo xiao er ke yi xue hui za zhi [Pubmed.gov] 1993; 34(1):45-53.

20. Sliman GA, Winters WD, Shaw DW, Avner ED. Hypercalciuria and nephrocalcinosis in the oculocerebrorenal syndrome. J Urol 1995; 153(4):1244-6.

21. Greenbaum LA. Electrolyte and acid-base disorders (chapter 52). In: Kliegman RM, Behrman RE, Jenson HB, Stanton BF (eds.). Nelson Textbook of Pediatrics. 17th Edition. Philadelphia: WB Saunders. 